206 EL TALLER DE LA HISTORIA 2

\title{
LAS FRONTERAS EN LA HISTORIA HISPANOAMERICANA: NOTAS SOBRE ALGUNAS TENDENCIAS
}

\begin{abstract}
José Polo Acuña *
De alguna manera, toda historia humana es una lucha del hombre por someter el entorno que lo rodea, por domesticar la naturaleza e implantar su poder, en una encarnizada lucha por extender su dominio hacia territorios inexplorados. En Hispanoamérica, a diferencia de Europa, esta lucha sigue marcando las realidades políticas, culturales y económicas que han tenido una larga trayectoria histórica. Por ejemplo, desde el mismo momento del desembarco de los españoles en el "Nuevo Mundo", en su afán de someter territorios y pueblos aborígenes, su control no fue total, y se fueron conformando espacios que escaparon a todo tipo de sujeción por parte del Estado colonial y posteriormente republicano.

Las causas y procesos por los cuales se fueron consolidando este tipo de espacios son de diversa índole, y los estudiosos que han investigado sobre ello difieren en la construcción conceptual que le han dado. En este sentido, el propósito de estas breves notas es el de establecer unas tendencias temáticas acerca de los estudios históricos que se ocupan de las fronteras, analizando para ello algunas obras representativas que muestran, de una $\mathrm{u}$ otra forma, la influencia de las fronteras en los procesos políticos y socio-culturales de las naciones hispanoamericanas. Este análisis también nos sirve como pretexto para reseñar cuatro trabajos que abordan la historia fronteriza, publicados entre 1999 y 2001: Los caminos al
\end{abstract}

\footnotetext{
* Facultad de Ciencias Humanas, Programa de Historia, Universidad de Cartagena.
} 
río Magdalena: La Frontera del Cararey del Opón 1760-1860', es el título del texto de Aristides Ramos Peñuela. Mestizaje, Comercio y Resistencia: La Guajira durante la segunda mitad del Siglo XVILI, es el encabezado que acompaña la investigación de Eduardo Barrera Monroy ${ }^{2}$. Y, Ni aniquilados, ni vencidos: Los Emberá y la Gente Negra del Atrato bajo el Dominio Español Siglo XVILI, es el trabajo de Erik Wemer Cantor ${ }^{3}$. Finalmente, La frontera española en América del Norte, es el título del texto del profesor David Weber, reconocido investigador de la historia de las fronteras en el sur de Estados Unidos y norte de México ${ }^{4}$.

En un primer momento, Sergio Villalobos, refiriéndose a las fronteras chilenas de Tarapacá y Araucania, las define como zonas donde el mestizaje y la violencia estaban a la orden del día; esta última fue utilizada para desalojar a los indígenas de sus tierras y en aprovechamiento de su desorganización social; en fin, espacios donde hombres y mujeres enlazaron cuerpos y culturas. ${ }^{5}$

Frederick Jackson Tumer, norteamericano, pionero en la investigación sobre la frontera oeste norteamericana, afirmaba que la frontera suponía la existencia de una tierra libre y el continuo avance de colonos presionando sobre la misma. Sostenía, además, que la frontera había contribuido a la formación de un espíritu li-

1. Aristides Ramos Peñuela, Los Caminos al Río Magdalena: La Frontera del Carare y del Opón 1760-1860. Santa Fe de Bogotá, Instituto Colombiano de Cultura Hispánica, 1999, 178 p.

2. Eduardo Barrera Monroy, Mestizaje, Comercio y Resistencia: La Guajira durante la segunda mitad del Siglo XVIII. Santa Fe de Bogotá, Instituto Colombiano de Antropología e Historia, 2000, 246 p.

3. Erick Werner Cantor, Ni aniquilados, ni vencidos: los Emberá y la Gente Negra del Atrato bajo el Dominio Español. Siglo XVIII. Santa Fe de Bogotá, Instituto Colombiano de Antropología e Historia, 2000, 199 p.

4. David Weber, La Frontera Española en América del Norte. México, Fondo de Cultura Económica, 2000. 599 p. La primera edición de este texto apareció en lengua inglesa en 1992, bajo el título de The Spanish Frontier in North America. Yale University, 1992.

5. Sergio Villalobos, La vida fronteriza en Chile. Madrid, Mapire, 1992. Capítulo introductorio. 
208 EL TALLER DE LA HISTORIA 2

bertario que posteriormente consolidó las instituciones democráticas en los Estados Unidos ${ }^{6}$. No está muy lejos otro norteamericano, Arthur S. Aitón, cuando sostiene que las condiciones fronterizas desarrollaron un espíritu individualista, de resistencia e iniciativa democrática ${ }^{7}$.

Por su parte, en pleno siglo XIX, Domingo Faustino Sarmiento, escritor, educador y presidente de Argentina entre 1868 y 1888 , planteó el problema de la frontera y la no frontera en términos de barbarie y civilización. Para él, la ciudad era el espacio donde se encontraba la civilización (Buenos Aires); sus habitantes eran blancos, descendientes de europeos. La frontera, la gran pampa argentina, era el lugar de lo bárbaro, del gaucho que no vivía conforme a las leyes 8 .

De otro lado, el historiador peruano Víctor Andrés Belaúnde, comparte con Tumer el hecho de darle importancia a las fronteras en la historia americana, sin embargo, difiere de él cuando plantea que, la rigidez de las instituciones coloniales en Hispanoamérica no hicieron fluida y dinámica la frontera como sí sucedió en Norteamérica. Belaúnde llega a esta conclusión después de establecer comparaciones entre las zonas bañadas por los ríos Missisipi y Amazonas, las montañas Alleghenies con los Andes, y la existencia de tierras bajas tropicales con las complejas montañas de México'.

Este grupo de estudios a los que hemos hecho referencias, sin pretender ser exhaustivos, los podemos enmarcar, con el riesgo de

6. Frederick Jackson Turner, La frontera en la historia americana. San José, Universidad Autónoma de Centroamérica, 1986. El texto original apareció publicado por vez primera en Annual Report of the American Historical Association. Washington, D.C., Government Printing Office, 1894, pp. 199-227.

7. Arthur S. Aitón, "Latin-American Frontiers", Canadian Historical Association Report. Ottawa, Canadian Historical Association / Société Historique du Cañada, 1940, pp. 100 104.

8. Domingo Faustino Sarmiento, Civilización y Barbarie (vida de Don Juan Facundo Quiroga). México, Porrúa, 1977.

9. Víctor Andrés Belaúnde, "The Frontier in Hispanoamérica", en Rice Institute Pamphlets. Houston, Rice University, 1923, pp. 202-213. 
caer en esquematismos, en una tendencia que trata de encontrar el significado de la frontera en los procesos históricos de América ${ }^{10}$.

Otro grupo de estudios se centra en los pueblos fronterizos y sus instituciones. En este orden de ideas, emergen las misiones religiosas como objetos de investigación para dar cuenta tanto de las relaciones inter-étnicas entre aborígenes y blancos, así como también relaciones de dominación. En esta línea, las misiones en territorios fronterizos se convirtieron de hecho en una institución de control social, aculturación y deculturación de los grupos indígenas que allí habitaban". Sin embargo, los misioneros no fueron los únicos bastiones de avanzada en las fronteras, sino que en muchas ocasiones compartieron su presencia con los militares, quienes los apoyaban en su labor evangelizadora. Los militares construyeron fuertes para resguardarse de los ataques nativos y preparar desde allí campañas de pacificación; pero, de hecho, lo que hicieron fue acomodarse a un modus vivendi con las sociedades aborígenes $^{12}$, una especie de negociación que dio origen a lo que podríamos denominar una cultura fronteriza ${ }^{13}$.

10. En este sentido, y en adelante, en cuanto al agrupamiento de las investigaciones sobre fronteras, nos hemos apoyado en el trabajo compilatorio de David Weber y Jane Rausch, Where Cultures Meet. Frontiers in Latín American History. Wilmington, Jaguar Books, 1994.

11. Véase, por ejemplo, a David Sweet, "Reflections on the Ibero-American Frontier Mission as an Institution in native American History", en New Latin American Mission History. Nebraska University, 1994.

12. Véase a Louis de Armond, "Frontier Warfare in Colonial Chile", en: Pacific Historical Review, 23, 1954, p.p. 125-132. De igual forma a Sergio Villalobos, La vida fronteriza en Chile. Madrid, Mapfre, 1992. También ofrece una interesante síntesis David Weber, La Frontera Norte de México 1821-1846. Madrid, Mapfre, 1992. Para una discusión en el contexto teórico acerca de la aculturación, puede leerse a Nathan Wachtel, Los vencidos: Los Indios del Perú y el Desafío de la Conquista Española 1530-1570. Madrid, Alianza, 1978.

13. Este concepto lo retomaremos más adelante cuando hagamos alusión al caso colombiano. Sin embargo, ya hay ciertos estudios concretos que sugieren la posibilidad de abordar las fronteras como un todo bajo la esfera cultural. Véase al respecto la compilación de Tino Villanueva (compilador), Chícanos: Antología Histórica y Literaria. México, Fondo de Cultura Económica, 1994. Igualmente véase a José David Saldívar, Las Fronteras de Nuestra América: para volver a trazar el mapa de los estudios culturales norteamericanos. La Habana, Casa de las Américas, 204, 1996, pp. 3-19. 
210 EL TALLER DE LA HISTORIA 2

Pero las relaciones entre grupos humanos en las fronteras no se redujo únicamente a indios y blancos, sino que también incluyeron a mestizos y negros esclavos que escaparon al control del Estado colonial y fundaron sus propias comunidades, denominadas palenques en Hispanoamérica y quilombos o mocambos en Brasil. Estos grupos, considerados por un historiador Jamaicano como transfronterizos, encontraron en la frontera una alternativa temporal a la rígida estructura social de la colonia en la cuenca del Caribe ${ }^{14}$. Precisamente, esa alternativa también permitió el asentamiento de colonos blancos con sus familias, que creyeron encontrar en la frontera una válvula de escape que le aliviara su difícil situación. Sin embargo, es importante anotar que la frontera también fue un escenario de confrontaciones sociales, no sólo entre colonos e indígenas y negros, sino entre las élites, que vieron en esos espacios la oportunidad para consolidar sus planes de poder a sangre y fuego.

Finalmente, y para culminar este breve recorrido por las acepciones que ha tenido el concepto de frontera a través de algunas obras representativas, se encuentra una tendencia de estudios que se centra en los pueblos fronterizos y su relación con el problema de la identidad nacional. En este orden de ideas, son conocidos los casos de gmpos humanos que consolidaron su existencia en las fronteras, y que sus imágenes, de una u otra forma y de manera ambivalente, fueron utilizadas por las clases dirigentes hispanoamericanas para impulsar, sobre todo después de la segunda mitad del siglo XIX, el mito de la identidad nacional. Al lado de los pioneros norteamericanos que, según el mito, encamaron virtudes

14. Franklin W. Night, The Caribbean: The Génesis of FragmentedNationalism. Oxford University Press, 1990, especialmente las páginas 90-96. Un sugestivo trabajo, que se incluye en esta revista, es el de Marta Herrera Ángel, "El arrochelamiento: nominar para criminalizar", donde plantea el hecho de que esos espacios fronterizos, poblados por "gentes dispersas", no carecían de orden como querían hacer ver los contemporáneos que rindieron informes sobre ellos. Más bien fue un orden alternativo diferente al planteado por el Estado colonial. 
como la del hombre trabajador, con espíritu de iniciativa, fidelidad a los valores religiosos, y a las cuales se fueron agregando otras como los fuertes leñadores, el indígena luchador, entre otras tantas; se hayan otros dos casos interesantes de abordar: los bandeirantes de Brasil y los gauchos de Argentina ${ }^{15}$.

En un libro publicado en 1942, Ricardo Cassiano llegaba a las siguientes conclusiones acerca de la importancia de los bandeirantes en la construcción de la nación brasilera:

Primero, gracias a los bandeirantes, Brasil pudo extender su territorio, originalmente circunscrito a los términos territoriales del Tratado de Tordesillas. Segundo, consecuentemente, contribuyeron con la exploración del territorio suramericano, galopando por el Sertao o regiones inhóspitas en busca de oro y esmeraldas. Tercero, fueron eslabones que permitieron la mixtura racial. Y cuarto, fueron grupos anónimos que lograron construir una especie de espíritu democrático ${ }^{16}$.

Aunque Cassiano olvidó que la principal actividad originaria de los bandeirantes fue la cacería de indios durante el siglo XVII y el saqueo de los recursos de las comunidades nativas, su texto contribuyó a generar unas imágenes de los bandeirantes como pioneros de avanzada en la construcción de la nación brasilera.

El caso de los gauchos, de la pampa argentina, también reviste cierta similitud con el de los bandeirantes. Atrapado entre su intransigente amor a la libertad y a las leyes que los forzaron a defenderse de los indígenas, fueron desapareciendo gradualmente de la escena social, cuando el espacio que habitaban fue incorporado

15. Puede verse el interesante ejercicio comparativo que hace Hebe Clementi entre pioneros norteamericanos, los bandeirantes brasileros y los gauchos argentinos. "National Identity and the Frontier", American Studies International 18, 1980, pp. 36-44. Para una comparación entre bandeirantes brasileros y pioneros norteamericanos, véase además a Clodomir Vianna Moos, "Bandeirantes and Pionners", en: David Weber y Jane Rausch (editores,), Where Cultures Meet: Frontiersin Latin American History. Willmington, Jaguar Books, 1994, pp. 165-176.

16. Ricardo Cassiano, Marcha para Oeste (A Influencia da "Bandeiro" na Formaçao Social e Política do Brasil). 2 vols. Río de Janeiro, Librería José Olimpo, 1959. 


\section{EL TALLER DE LA HISTORIA 2}

al territorio nacional argentino. Las imágenes que de él se tienen son ambivalentes: de un lado, se les describe como discretos, hospitalarios, pacientes e ingeniosos, de otra, se les endilga de crueles, perezosos, pendencieros y cobardes ${ }^{17}$. Sea como fuere, la imagen del gaucho fue insigne de la representación nacional argentina a partir de la década de $1890^{18}$.

Independientemente del uso de las imágenes de los pueblos fronterizos por parte de la clase dirigente hispanoamericana, estamos de acuerdo con el llamado de atención que hace Hebe Clementi en el sentido de dedicarle más análisis y reflexiones a la historia de las fronteras y su relación con el problema de la nación. Y esto no es menos cierto para un país como Colombia, que a través de su historia ha vivido un contrapunteo constante entre lo que podríamos denominar "espacios mayores" o de inclusión, representado fundamentalmente en las ciudades, y los "espacios menores" o de exclusión, encamados en las fronteras. La Guajira, el Darién, parte del Magdalena Medio, los Llanos Orientales, parte del Valle del Patía y el Amazonas, entre otros, son la herencia visible y actualizada de la frontera. E inclusive, el actual conflicto armado se desarrolla en muchas de estas zonas, configurándose de esta manera lo que María Teresa Uribe llama una "territorialidad de los conflictos En este orden de ideas, y siguiendo a la mencionada autora, las fronteras en Colombia terminaron por convertirse en unas "soberanías en disputa"'entre los actuales actores armados del conflicto ${ }^{19}$.

17. Hebe Clementi, Op. cit., pp. 36-44.

18. Para unas reflexiones sobre cómo algunos intelectuales, escritores y políticos argentinos comenzaron, a partir de la década de 1890, a convertir al gaucho en símbolo de la identidad nacional, véase a Richard Salta, "The Gaucho in Argentina's Quest for National Identity", en: Canadian Review of Studies in Nationalism, 12, № 1, 1995, pp. 99-122. Relacionado con este mismo aspecto, y en general con el uso de las imágenes del otro, véase a Javier Lasarte, "Tú no eres él: diversidad de las representaciones del otro", en: Beatriz González, Javier Lasarte y Graciela Montaldo (compiladores), Esplendores, Miserias del Siglo XIX: Cultura y Sociedad en América Latina. Caracas, Monteávila, 1995, pp. 221-241.

19. María Teresa Uribe de Hincapié, "La territorialidad de los conflictos y la violencia en Antioquia", en Realidad Social, t.I, Departamento Administrativo de Planeación, 
De manera, pues, que la investigación sobre las zonas fronterizas en Colombia está a la orden del día, y es urgente seguir ahondando sobre ellas. Precisamente, este preludio es el que nos permite reseñar y comentar cuatro libros publicados en el lapso de tres años, 1999 y 2001, sobre la historia de las fronteras: Tres de ellos sobre Colombia y uno sobre México. Los tres primeros se refieren a tres zonas importantes durante el siglo XVIII: El Carare y el Opón, el Alto y Medio Atrato, y la Guajira. Tres puntos que constituyen un triángulo cuyas bases se encuentran de este a oeste, y el vértice que las une, al norte. Tres zonas neurálgicas que preocuparon permanentemente a las autoridades coloniales y cuya dinámica envolvió a colonos blancos, indígenas, mestizos, negros, militares, misiones religiosas y hasta empresarios. El cuarto libro es una síntesis acerca de la frontera española en América del Norte, y nos sirve como referencia comparativa para extender la mirada sobre otras dinámicas fronterizas que se dieron en otras latitudes.

Aparte de analizar la historia de espacios fronterizos durante el siglo XVIII, los tres primeros trabajos comparten otros elementos en común: corresponden a tres monografías de grado de maestrías y pregrado de la Facultad de Ciencias Humanas de la Universidad Nacional de Colombia. Los textos de Eduardo Barrera y Aristides Ramos son, en esencia, las tesis que ambos presentaron para optar al título de Magíster en Historia, en 1992 y 1998 respectivamente. El trabajo de Erik Wemer es, en gran parte, su mono-

\footnotetext{
Gobernación de Antioquia, Medellín - Edinalco, 1990. "Las soberanías en disputa, ¿conflicto de identidades o de derechos?”, en: Gonzalo Sánchez y María Emma Willa (compiladores^, Museo, Memoria y Nación: Misión de los Museos Nacionales para los Ciudadanos del Futuro. Santa Fe de Bogotá, Museo Nacional de Colombia / Ministerio de Cultura / Iepri / Icanh, 2000, pp. 455-479. De otro lado, Malcolm Deas ha señalado, refiriéndose a un ejercicio de historia comparativa entre los espacios del Táchira (Venezuela) y Santander (Colombia), que el "interés en la frontera deriva de la sospecha que tal vez allá se encuentran varias explicaciones, o sugerencias de explicaciones de las diferencias, de por qué Colombia es Colombia y Venezuela es Venezuela". Malcolm Deas, "Temas comparativos en la historia republicana de Colombia y Venezuela", en Víctor Manuel Uribe y Luis Javier Ortiz (editores académicos), Naciones, Gentes y Territorios. Ensayos de historia e historiografía comparada de América Latina y el Caribe. Medellín, Universidad Nacional de Colombia, 2000, pp. 305-319.
} 
grafía para optar al título de antropólogo. Las tres investigaciones fueron pensadas, diseñadas y ejecutadas en el marco del entonces Taller de Etnohistoria, dirigido en ese momento por el profesor Hermes Tovar Pinzón.

Tanto Mestizaje, Comercio y Resistencia: La Guajira durante la segunda mitad del siglo XVIII, de Barrera; como Ni aniquilados, ni vencidos: Los Emberá y la gente negra del Atrato bajo el dominio español. Siglo XVIII,de Wemer Cantor; le dedican su atención a grupos humanos "subordinados o subalternos" de la sociedad colonial neogranadina: Los wayúu de la península de la Guajira y los emberá y la "gente negra" del Atrato. Ambos trabajos, desde el punto de vista conceptual y metodológico, son deudores de la tendencia etnohistórica que iniciaron décadas atrás Charles Gibson, Nathan Wachtel, Steve Stem, Jhon V. Murra, Franklyn Pease, Alberto Flores Galindo, Nancy Farris, Serge Gruzinski y William Taylor, entre otros ${ }^{20}$.

Esta tendencia etnohistórica desplaza el foco de observación de los "colonizadores" a los "colonizados", de los "vencedores" a los "vencidos". En este sentido, Eduardo Barrera plantea que, su trabajo "...se ha propuesto recuperar en lo posible, la perspectiva indígena, la visión de los wayúu, y los elementos que de esta cultura sirven para explicar los conflictos del siglo XVIII"'21. Se refiere el autor a la confrontación entre los wayúu y los "aljunas" por el

20. Charles Gibson, Los Aztecas bajo el dominio colonial. México, Siglo XXI, 1965. Nathan Wachtel, Los vencidos: Los indios del Perú frente a la conquista española (15301570). Madrid, Alianza, 1992. Steve Stern, Los indios del Perú y el desafio de la conquista española. Madrid, Alianza, 1992. Jhon Murra, Una apreciación etnológica de la visita: Visita hecha a la provincia de Chucuita por García Diez de San Miguel en el año 1567. Lima, Instituto de Estudios Andinos, 1964. Franklyn Pease, Del Tawantunsuyu a la historia del Perú. Lima, Instituto de Estudios Andinos, 1976. Alberto Flores Galindo, En busca de un Inca: Identidad y Utopía en los Andes Centrales. Lima, Instituto de Estudios Andinos, 1985. Nancy Farris, Los Mayas bajo el dominio español Madrid, Alianza, 1992. Serge Gruzinski, La colonización de lo imaginario: Occidentalización y resistencia indígena en el México Colonial (siglos XVI -XVIII). México, Fondo de Cultura Económica, 1992. William Taylor, Embriaguez, homicidio y rebelión en las poblaciones coloniales de México. Madrid, Alianza, 1989. 
control de la península de la Guajira, manifestada a través de varias facetas que comprendían procesos de colonización por la Media y Alta Guajira, el impulso a misiones religiosas capuchinas, la erección de pueblos de indios, el contrabando, procesos de mestizaje, campañas militares de pacificación, designación de líderes indígenas que sirvieran de intermediarios entre las autoridades españolas y el grueso de la población nativa no sujeta, y los enfrentamientos armados. Wemer Cantor, por su parte, sostiene que su trabajo “...pretende describir y analizar el proceso de colonización española en el Alto y Medio Atrato durante el siglo XVIII y su impacto sobre los procesos sociales y culturales de los indios y negros" 22 . En este orden de ideas, Wemer Cantor analiza procesos como el poblamiento del Alto y Medio Atrato y la conformación de lo que en el siglo XVIII se denominó Provincia de Citará, que limitaba al norte con el Bajo Atrato, territorio de los indios cuna; al sur, con el río San Juan; al oeste, con la Baja Serranía del Baudó y al este con la Cordillera Occidental (véase capítulo 1, pp. 29-88). De otro lado, la investigación de Barrera se centra en lo que se conoció con el nombre de provincia del Río de la Hacha, una comandancia de la gobernación de Santa Marta, cuya capital era la ciudad de Riohacha. Sólo hasta 1789 se deslindó de Santa Marta y se convirtió en gobernación independiente. Sus límites durante el siglo XVIII fueron muy vagos: por el este, limitaba con el Cabo de Coquibacoa, siguiendo la costa hasta el río Sucuy en la Laguna de Maracaibo, por el sur con la Sierra Nevada de Santa Marta y la provincia de su mismo nombre. Como se ve, dos espacios físicos diferentes: mientras en la provincia de Citará predominaban abundantes lluvias, vegetación y recursos mineros (oro), en la provincia de Riohacha existía una gama de paisajes, pero se daba fundamentalmente el semi-desértico y con escasez de metales preciosos.

Ambos autores nos muestran a lo largo de los capítulos que fueron distintas tanto las estrategias de dominación por parte de los españoles, como las respuestas de los grupos "sometidos" (los emberá-catío y los negros esclavos en la provincia de Citará. Los 


\section{EL TALLER DE LA HISTORIA 2}

wayúu en la Guajira). En efecto, los wayúu, aprovecharon el medio fronterizo abierto para hacerse fuertes a través del contrabando y el proceso de mestizaje. Mediante el primero, lograron adquirir de ingleses y holandeses las armas de fuego que emplearon tanto contra los colonos hispano-criollos como de los soldados de la corona (véase el capítulo IV de Barrera, Los Conflictos, pp. 173220). A través del segundo, fueron incorporando a su universo socio-cultural a los colonos españoles y a los negros esclavos; por lo tanto, en el proceso de mestizaje predominaron los elementos culturales wayúu. Esto estuvo acompañado de otro tipo de transformaciones en la sociedad nativa como la adopción del ganado, en especial del caballo, que asumieron en excelentes condiciones para ajustarlo a sus necesidades (véase el capítulo I, Espacio y Sociedad, pp. 25-76).

Otros indicios de cambios importantes en la comunidad wayúu fueron, de un lado, la pesca de perlas, actividad que a mediados del siglo XVI estaba en manos de españoles, pero que en el siglo XVIII ya estaba controlada por los indios "perleros" o "buzos" que habitaban el asentamiento de Carrizal, ubicado entre el Cabo de la Vela y Riohacha. De otro, el corte de palo brasil que extraían de la Serranía de la Macuira y de las estribaciones de los Montes de Oca, les proporcionó un contacto constante con los holandeses, quienes establecieron toda una red comercial de este producto en el Caribe (véase el capítulo II: Las economías: Las bases productivas, pp. 77-118). Todas estas transformaciones le permitieron a la comunidad wayúu establecer relaciones de comercio y de intercambio con contrabandistas ingleses, holandeses y franceses, entre otros, y les aseguró una red de apoyo que redundó en el aumento de su autonomía frente a los españoles (véase capítulo III, Las economías: La Circulación, pp. 119-171). Termina Barrera su texto sosteniendo, además, que los wayúu supieron mantener un principio de reciprocidad encamado en la ley de cobro, que les posibilitó mantenerse en pie de fuerza frente a las embestidas de los colonos hispano-criollos y de las tropas españolas de pacificación.

Sin duda, el trabajo de Barrera constituye un aporte serio a la historia colonial colombiana y del caribe en particular; sin embar- 
go, algunos elementos de su argumento central (el principio de reciprocidad - ley de cobro), hubieran merecido un tratamiento más sistemático que involucrara variables interconectadas entre sí. Por ejemplo, se resiente en el texto un tratamiento más profundo del proceso de poblamiento en la Guajira durante el siglo XVIII, pues éste hubiera mostrado las concepciones antagónicas con respecto al espacio y el territorio que tenían tanto los "alijunas" como los españoles. Y ello iba mucho más allá, porque territorio y parentesco en la sociedad wayúu están íntimamente relacionados. Esto, inclusive, explicaría por qué en los enfrentamientos armados entre nativos y españoles la estructura de los movimientos wayúu estaba signada por las relaciones parentales, que en últimas, sustentaban tanto el principio de reciprocidad como la ley de cobro ${ }^{23}$. De otro lado, fenómenos tan importantes en las zonas fronterizas como el contrabando y el mestizaje necesitan otros elementos conceptuales de análisis que develen en una forma más profunda los entramados sociales, étnicos y de poder que allí se entretejieron. Se sabe, por ejemplo, que los líderes de los grandes apüshis* de la Alta Guajira establecieron alianzas directas con redes de contrabandistas provenientes de Curazao y Jamaica, quienes arribaban a los puertos naturales del norte de la Guajira para contrabandear toda clase de géneros. Pero estas alianzas iban mucho más allá del mero contacto comercial y de intercambios de productos, pues los wayúu, paradójicamente, hacían bautizar a sus hijos de estos contra-

23. Para el proceso de poblamiento véase a José Polo Acuña, "Poblamiento y Conflicto Social en la Frontera Guajira (1700-1800)", El Taller de la Historia, 1, Universidad de Cartagena, 2001, pp. 27-78. Para una relación entre parentesco y territorio en los wayúu durante el siglo XVIII, véase a José Polo Acuña, "Contrabando y Pacificación Indígena en una Frontera del Caribe Colombiano: La Guajira 1750-1800", Aguaita (Revista del Observatorio del Caribe Colombiano), 3, 2000, pp. 41-62. Para una relación entre movimientos armados wayúu y las relaciones parentales véase también a José Polo Acuña, Protesta y Resistencia Indígena en la Guajira 1750-1800. Tesis para optar al título de Magíster en Historia. Bogotá, Universidad Nacional, 1999.

* El apüshi es un grupo residencial de hombres y mujeres, hermanos y hermanas alrededor de un territorio. Es el sitio de una red de cooperación entre parientes, que comparten recursos y un cementerio. 
218 EL TALLER DE LA HISTORIA 2

bandistas y de capitanes de embarcaciones extranjeras. Ello, sin duda, consolidó los lazos entre la comunidad nativa y todo lo que provenía de la cuenca del Caribe, conformándose lo que Zacarías Moutouquias denomina Redes Ego a través del contrabando ${ }^{24}$.

Wemer Cantor, por su parte, nos describe inicialmente la instauración de las instituciones españolas en la provincia de Citará, la fundación de pueblos de indios mediante la negociación entre los citaraes y los colonos (Negua, Lloró y Quibdó, en 1688; Bevará, en 1693; Murrí, en 1711; Beté, en 1719; Cupica y Pavarandó, en 1773) y el desplazamiento de los indios cuna al Bajo Atrato, al istmo de Panamá y el Darién. A diferencia de la Guajira, la provincia del Citará era rica en oro, por lo que los españoles establecieron tres distritos mineros: el partido de Quibdó, el de Lloró y el de Bevará. Como ya no los mostró en alguna ocasión Germán Colmenares y Jaime Jaramillo Uribe, Wemer Cantor nos describe la población negra esclavizada, su procedencia, la manera como desarrollaban su trabajo en las minas, edad y sexo; todo ello enmarcado en la unidad productiva que agrupaba y organizaba el trabajo de los negros: la cuadrilla.

Posteriormente, el autor describe la conformación de las estructuras de dominación a través de los poderes locales: los funcionarios reales (corregidor de naturales), las misiones franciscanas y los dueños de minas y de cuadrillas procedentes de Popayán y Cali. En estos últimos estaba fundada una verdadera tradición de poder, que también estuvo sustentada en el control de los puestos de mando. La élite indígena, por su parte, no estuvo ausente de estas estructuras de dominación, pues sacaron ventaja de su posición de intermediaria entre los españoles y los nativos citaraes.

Pero si las estructuras de dominación se consolidaban en la provincia de Citará, el Bajo Atrato, al igual que el norte de la Guajira, fue un territorio independiente del imperio español, controlado por los indios cuna (pueblos de Tarena, Arquía, Caimán, Care-

24. Zacarías Moutouquias, "El Concepto de Redes en Historia Social: un instrumento de análisis de la acción colectiva”. Copia mecanografiada, 1996. 
pa), que se convirtió en un escenario de contrabando y de penetración permanente de extranjeros quienes intercambiaban con los cunas escopetas, pólvora, ropa, licor y en general toda clase de géneros provenientes de Jamaica y Curazao.

En la última parte de su texto, Wemer Cantor describe y analiza la respuesta de los indios y de los negros a la colonización española, que comprendían el cimarronismo, huidas individuales, ataques a los amos, la preservación de la lengua y el traje indígena y hasta la constmcción de bohíos en las afueras de los poblados. Finalmente, el autor hace algunas reflexiones sobre la continuidad del proceso de constmcción social y cultural de los negros, mostrando cómo el proceso de mestizaje y la conformación de las familias en las minas fue originando una organización social que aún deja sus huellas.

Interesante resulta el análisis que hace Wemer Cantor sobre las casi nulas relaciones interétnicas entre los indios y negros, más bien distanciamiento, producido por las políticas de segregación de los dos gmpos impulsadas por los blancos. Por una parte, los indios rechazaban el pesado trabajo de horticultura y pesca para sostener a las cuadrillas de negros; por otra, los españoles siempre fueron temerosos de una posible alianza entre estos dos grupos para desestabilizar el orden. Esto fue contrario a lo que sucedió con la población negra en la Guajira, que fue, como decíamos anteriormente, asumida por los wayúu e incluida en su universo socio-cultural.

Si la preocupación en los trabajos de Barrera Monroy sobre la Guajira, y de Wemer Cantor sobre el Atrato son los grupos étnicos "sometidos" y su respuesta a las políticas de colonización y sujeción impulsadas por los españoles, la de Aristides Ramos en Los Caminos al Río Magdalena. La Frontera del Carare y del Opón 1760-1860, es de otra índole: develar el interés de empresarios y el Estado por "....arrebatarle a la selva sus recursos, con destino al mercado mundial..." (p. 14), lo que dio origen a "una red de caminos, aldeas y varadores en las selvas, estratégicamente situadas para facilitar la comunicación de las zonas de extracción con las 


\section{EL TALLER DE LA HISTORIA 2}

vías que darían salida al exterior a aquellos productos" (p. 14). En este sentido, el poblamiento y la explotación de recursos en las cuencas de los ríos Carare y Opón, tributarios del río Magdalena, territorios de frontera de las provincias de Vélez y El Socorro, "fueron escenario donde actuaron empresarios y colonos en los procesos de fundación y poblamiento de aldeas asociadas a la apertura de caminos en la zona" (p. 15). Estos procesos se desarrollaron entre 1760 y 1860 , período en el cual se adelantaron los proyectos de mayor importancia para la fundación de aldeas y poblamiento en la región del Carare y del Opón, impulsados inicialmente por el Estado colonial y después por los primeros gobiernos republicanos.

La hipótesis planteada por Aristides Ramos sostiene que la fundación y el poblamiento de aldeas en la región del Carare y del Opón "fue el resultado de la concepción de políticos e intelectuales que expresaron en sus discursos que el desarrollo económico se lograría con base en el aumento de las exportaciones agrícolas habilitando para ello nuevas tierras y adicionalmente fortaleciendo los intercambios comerciales internos con base en la apertura de nuevos caminos, estimulando con ello el poblamiento de las zonas de fronteras, consideradas estratégicas para unos proyectos comerciales concebidos como inaplazables para el desarrollo económico de las provincias agrícolas y manufactureras del nororiente colombiano" (pp. 15-16). En este sentido, Ramos analiza las circunstancias sociales que caracterizaron la primera etapa de apertura de caminos en la zona, sobre todo estudiando la capitulación o contrato que suscribió el empresario Blas de la Terga, que reflejó la importancia que tuvo la región del Carare para las élites de la provincia de Vélez. En este orden de ideas, el autor muestra también el conflicto de intereses que este tipo de capitulaciones generó entre los empresarios, el cabildo y las élites provinciales.

En el transcurso de este proceso se fundaron varias compañías y se estipularon algunas capitulaciones que, en términos generales, planteaban la provisión de bienes de consumo y de productos agrícolas a las provincias de Antioquia, que durante este período recobraban su importancia como zona minera. La Compañía del 
Opón, por ejemplo, conformada a finales del siglo XVIII y dirigida por el presbítero Don Ramón Blanco y Viana, tuvo como objetivos el abastecimiento de productos agrícolas y artesanales de las tierras del Socorro y Vélez, a las ciudades de Santa Marta y Cartagena. Esta compañía se propuso además hacer transitable el camino del Opón y erigir tres poblados en los sitios de Boca del Monte, Opón y San Silvestre. Sin embargo, tuvo que enfrentar la oposición de los indios Yariguíes, cuya pacificación concentró los esfuerzos y la mayoría de los recursos de la empresa.

Fray Pedro Pardo, religioso, se sumó al interés por el camino del Carare. Para ello, solicitó a la Real Audiencia licencia para excavar antiguas sepulturas indígenas donde se creía había oro. Años después, hacia 1850, Manuel María Zaldúa suscribió un contrato para la construcción de un camino carreteable en la provincia de Vélez y la navegación del río Carare con buques de vapor.

En general, las preocupaciones tanto de los gobiernos virreinales durante el período colonial como de los republicanos durante el siglo XIX con respecto a estas zonas fronterizas siguieron siendo, en esencia, las mismas: construir caminos carreteables, mejorar la navegación de los ríos, vincular comercialmente las diversas regiones, colonizar los valles interandinos y reducir las comunidades indígenas que se opusieron a ello.

La Frontera española en América del Norte es el título que acompaña al trabajo del profesor David Weber, reconocido investigador sobre la historia de las fronteras españolas en el norte del "Nuevo Mundo". Con una narración fluida y amena, Weber explica el impacto que tuvo España en la vida, las instituciones y el entorno de los pueblos nativos norteamericanos y el impacto de Norteamérica en la vida y las instituciones de aquellos españoles que exploraron y poblaron lo que en la actualidad constituye Estados Unidos*.

* El profesor Weber es claro y enfático en afirmar su "afecto descarado por la histoire événementielle y cierta aversión por el reduccionismo de la gran teoría. He tratado de descubrir y explicar patrones y relaciones sin deducirlos de la teoría social. En la medida en que uso la teoría como recurso explicativo, lo hago con un espíritu de eclecticismo y 


\section{EL TALLER DE LA HISTORIA 2}

El trabajo del profesor Weber rompe con la "miopía" de los trabajos históricos que tratan el tema del origen de los Estados Unidos, que invisibilizaron la herencia hispánica en Nuevo México, Arizona, Texas y Florida. Para ello, se aparta de la idea de que la frontera es el confín de la civilización y plantea que las mismas "...se entienden mejor como zonas de interacción entre dos culturas diferentes, como lugares en que las culturas del invasor y del invadido contienden entre sí y con su entorno físico para producir una dinámica que es única en tiempo y espacio. Como tales, las fronteras representan tanto un lugar cuanto un proceso, vinculados de manera inextricable" (p. 27).

Partiendo de la afirmación de que los indígenas norteamericanos y los españoles que se encontraron en las fronteras de Norteamérica no fueron capaces de entenderse, por provenir de mundos distintos, Weber nos describe lo que ha denominado "mundos aparte", presentando un crisol de variadas características de las comunidades aborígenes que habitaban el norte del actual México y sur de Estados Unidos, y de los españoles que llegaban a un mundo jamás imaginado por ellos (capítulo 1, pp. 31-51). Seguidamente, el autor expone de manera sistemática el proceso de descubrimiento y ocupación de Florida, Texas, Arizona y Nuevo México por parte de las expediciones de Ponce de León (1513), Álvarez de Pineda (1519), Estevao Gómez (1524-1525), Pedro de Quejo (1525), Cabeza de Vaca (1525-1536), De Soto (1539-1543), Coronado y Alarcón (1540-1542) y Cabrillo Ferrer (1542-1543); y las características de los primeros encuentros entre hispanos y aborígenes (Capítulo II, pp. 52-99). Una vez analizada esta primera etapa de exploración y reconocimiento del territorio, el profesor Weber nos introduce en la problemática de las contradicciones entre España, Inglaterra y Francia por el dominio de territorios fronterizos como Luisiana y Florida, entre otros. Dominio que implicó

de acuerdo con la observación de Clifford Geertz de "que las relaciones de una teoría general de casi todo lo social suenan cada vez más huecas, y las afirmaciones de quienes dicen tener una resultan megalomaniacas". "En este libro la explicación va inmersa en la narrativa", (p. 27, nota 38). 
no solamente una rivalidad imperial sino comercial con claras desventajas para España que no podía satisfacer las demandas de los habitantes de la frontera, quienes conseguían todo lo que necesitaban para su subsistencia de los ingleses, franceses y los llamados "indios agresores". Estos últimos mantuvieron en jaque la avanzada del imperio español: por el sur y oeste se encontraban los apaches, por el oeste los navajos, por el noroeste los utes y por el noreste los comanches. Estos aborígenes, al igual que los wayúu en la Guajira y los cuna del Darién, mantuvieron alianzas con los europeos y adquirieron de ellos armas de fuego, caballos y destrezas en el manejo de los mismos (véanse los capítulos VI, VII, VIII, IX y XX, pp. 217-422).

Pero si esto sucedía con los intentos de estabilización de la frontera con respecto a fuerzas externas, no menos problemática fue la consolidación de los poderes locales. En efecto, la frontera española en América del Norte osciló entre la explotación, la disputa y la rebelión. Contrariamente a la creencia popular, de que las fronteras son sitios de libertad y espíritu libertario, el profesor Weber plantea que las zonas fronterizas de recursos abiertos con frecuencia fomentan la servidumbre humana, no el trabajo en libertad. En este orden de ideas, se generó una competencia entre soldados, misioneros y empresarios por el control de la mano de obra nativa, rayando en la excesiva explotación y maltratos de los aborígenes, hasta el punto de que en 1680 desapareció casi por completo Nuevo México por un alzamiento de los indios Pueblo; pero inclusive antes: en Guale en 1597,1645 y principios de 1680; en Apalachee en 1647 y en Apalachicola en 1675 y 1681 entre otras zonas donde hubo enfrentamientos armados (capítulo V, pp. 181-216).

La herencia fronteriza de España en los Estados Unidos es el tema que aborda el capítulo XI (pp. 423-469), mostrando el profesor Weber cómo ha sido la transformación de las fronteras y sus pueblos, desde las estructuras materiales de la producción agrícola hasta las formas arquitectónicas de las construcciones.

Una institución importante en los territorios fronterizos, como vimos anteriormente, fueron las misiones religiosas. En este sen- 


\section{EL TALLER DE LA HISTORIA 2}

tido, el profesor Weber muestra cómo se implantaron, consolidaron y decayeron las misiones de los franciscanos en Florida y Nuevo México a mediados del siglo XVII. Ellos impulsaron una extensa red de pueblos de misión basados en su celo y constancia para enseñar las doctrinas cristianas, en el poderoso aparato burocrático y económico de la Iglesia y del Estado que los apoyaba y claro, en los mismos naturales, quienes decidían cuándo y cómo habrían de cooperar con los cristianos. Sin duda, ello hizo de los franciscanos unos verdaderos "conquistadores del espíritu" (capítulo IV, pp. 136-180).

Finalmente, en el último capítulo, el autor muestra y analiza de forma magistral el discurso histórico construido desde lo anglosajón acerca del pasado español de los Estados Unidos, haciéndole un análisis crítico a los estereotipos que ayudaron a conformar lo que el profesor Weber ha denominado una Hispanofobia, que iba desde la famosa leyenda negra hasta los prejuicios raciales. Concluye Weber su trabajo afirmando que esta negación y denigración del pasado español por parte de la historiografía anglosajona obedeció a la justificación del proyecto expansionista, primero de los ingleses y posteriormente del naciente Estados Unidos.

En horabuena, pues, llega el texto del profesor Weber, mostrándose una vez más que una de las funciones sociales de la historia, si nos atenemos a Eric Hobsbawm, es desmontar falsas tradiciones y quitar los velos que pesan sobre la "verdad" de los procesos históricos. 